Сахно $^{1}$ В.П., Шарай ${ }^{1}$ С.М., Мурований² І.С., Поляков ${ }^{1}$ В.М.

${ }^{1}$ Наиіональний транспортний університет

${ }^{2}$ Луцький національний технічний університет

\title{
ДОСЛІДЖЕННЯ ФАКТОРІВ ВПЛИВУ НА ЗАГАЛЬНІ ВИТРАТИ ВИКОНАННЯ ОБОРОТНОГО РЕЙСУ У МІЖНАРОДНОМУ СПОЛУЧЕННІ З ВИКОРИСТАННЯМ МАТЕМАТИЧНОї ТЕОРІї ЕКСПЕРИМЕНТУ
}

\begin{abstract}
В роботі розглянуті питання впливу різних статей загальних витрат (факторів) на розмір таких загальних витрат при виконанні оборотного рейсу доставки вантажів автомобільним транспортом у міжнародному сполученні.

Для розробки заходів щодо підвищення ефективності виконання процесу перевезень вантажів у міжнародному сполученні та зменшення загальних витрат на його виконання необхідно проводити аналіз статей витрат, які входять до складу загальних витрат. Для дослідження впливу окремих статей загальних витрат на виконання перевезень вантажів у міжнародному сполученні пропонується використання ефективних методів практичної реалізації системного підходу - методів математичної теорії експерименту або планування експерименту. При цьому вирішення задачі дослідження впливу окремих статей витрат (факторів впливу) на розмір загальних витрат проводиться на основі формування плану експерименту та створення експериментально-статистичної моделі.

В результаті розрахунків коефіцієнтів регресії за розробленою моделлю загальних витрат на виконання оборотного рейсу доставки вантажів у міжнародному сполученні та їх аналізу зроблено висновки щодо значущості коефіцієнтів, які формують найбільший вплив на розмір загальних витрат, та визначені статті витрат (досліджувані фактори впливу), що мають найбільший вплив на формування загальних витрат.

Ключові слова: загальні витрати, стаття витрат, міжнародні вантажні перевезення, оборотний рейс, фактор впливу, теорія планування експерименту.
\end{abstract}

\section{ВСТУП}

До складу загальних витрат на виконання перевезень вантажів у міжнародному сполученні входять витрати на паливно-мастильні матеріали, на заробітну плату водія (включаючи витрати на відрядження), на технічне обслуговування, на шини, на амортизацію, на організацію виконання перевезення тощо, які можуть розглядатися як фактори впливу на формування розміру загальних витрат.

Для дослідження впливу окремих статей загальних витрат на виконання перевезень вантажів у міжнародному сполученні 3 подальшою розробкою заходів щодо регулювання їх впливу на скорочення розміру загальних витрат можуть бути використані методи теорії планування експерименту. Застосування даних методів для аналізу факторів впливу на розмір загальних витрат при здійсненні доставки вантажів у міжнародному сполученні є актуальними для транспортних підприємств, основною діяльністю яких є виконання міжнародних вантажних перевезень.

\section{АНАЛІЗ ЛІТЕРАТУРНИХ ДАНИХ ТА ПОСТАНОВКА ПРОБЛЕМИ}

Аналізуючи систему доставки вантажів автомобільним транспортом у міжнародному сполученні можна виділити такі її початкові ланки: «вантаж - автотранспортний засіб - маршрут підприємство, що забезпечує виконання процесу доставки». Кожна ланка такої системи має свої компоненти. Кожен компонент у процесі планування, підготовки та виконання перевезень вантажів буде пов'язаний із витратами на його реалізацію. При здійсненні перевезень вантажів у міжнародному сполученні рухомим складом автомобільного транспорту на величину загальних витрат на виконання оборотного рейсу впливають такі витрати, як витрати на заробітну плату водія 3 урахуванням відшкодування витрат на відрядження, витрати на паливно-мастильні матеріали, витрати на технічне обслуговування, витрати на оформлення та організацію виконання перевезення тощо. Для аналізу загальних витрат на виконання оборотного рейсу доставки вантажів у міжнародному сполученні та розробки заходів щодо підвищення його ефективності та зменшення загальних витрат на його виконання можуть бути використані як аналітичні, так і експериментальні дослідження.

Експериментальні дослідження можуть бути замінені експериментом на моделі. Класична модель експерименту враховує ряд факторів, які можуть змінюватись при зміні умов проведення дослідження. 3 метою зменшення кількості проведених дослідів в основу досліджень може бути покладена математична теорія планування експерименту [1]. Питанням факторного експерименту 
присвячена велика кількість робіт, де обгрунтовується доцільність застосування одночасного варіювання різними факторами, які впливають на досліджувану результуючу величину [2-5].

При вивченні та дослідженні складних об’єктів, до яких відносяться і транспортні системи та транспортні процеси, які в них відбуваються, пропонується застосовування математичної теорії планування експерименту, якою передбачається формування плану експерименту [6].

Для вирішення задачі визначення загальних витрат на виконання перевезень вантажів у міжнародному сполученні, визначення ступеня впливу різних витрат на величину загальних витрат, пропонується формування плану експерименту та створення експериментально-статистичної моделі.

\section{ЦІЛЬ ТА ЗАДАЧІ ДОСЛІДЖЕННЯ}

Метою роботи є виявлення сумісного впливу низки факторів на загальні витрати при виконанні оборотного рейсу доставки вантажів у міжнародному сполученні з використанням математичної теорії планування експерименту.

Для досягнення мети необхідно вирішити такі задачі:

-аналіз факторів, які мають найбільшу вагу у загальних витратах на виконання оборотного рейсу доставки вантажів;

-формування плану експерименту;

-визначення розрахункових значень коефіцієнтів регресії та їх значущості;

-створення експериментально-статистичної моделі для розрахунку загальних витрат на виконання оборотного рейсу доставки вантажів.

\section{РЕЗУЛЬТАТИ ДОСЛІДЖЕНЬ}

Перед формуванням плану експерименту та визначенням вагомості впливу факторів на результуючу величину, необхідно мати результати розрахунків загальних витрат на виконання конкретного оборотного рейсу у міжнародному сполученні (результуюча величина) з визначенням статей таких витрат для різних умов його виконання: застосування одиночної та турної їзди, використання автотранспортних засобів, які мають різну лінійну норму витрат палива.

Загальні витрати на виконання оборотного рейсу «м. Київ (Україна) - м. Брно (Чехія) - м. Київ (Україна)» доставки м'ясної продукції за умови роботи 1 водія та використання автопоїзду у складі сідельного тягача Renault MAGNUM 460.19 T із напівпричепом-рефрижератором KÖGEL SV 24 наведені в табл. 1.

Таблиця 1 - Загальні витрати на виконання оборотного рейсу при одиночній їзді

\begin{tabular}{|l|c|}
\hline \multicolumn{1}{|c|}{ Стаття витрат } & Розмір витрати, грн. \\
\hline Фонд заробітної плати водія & 7874,40 \\
\hline Витрати на автомобільне паливо & 47195,99 \\
\hline Витрати на мастильні матеріали & 5663,52 \\
\hline Витрати на сервісне обслуговування & 109,59 \\
\hline Витрати на відновлення і ремонт шин & 1500,72 \\
\hline Витрати на оформлення перевезення & 7606,00 \\
\hline Амортизаційні відрахування & 6806,15 \\
\hline Загальногосподарські витрати & 11513,46 \\
\hline
\end{tabular}

Загальні витрати на виконання оборотного рейсу «м. Київ (Україна) - м. Брно (Чехія) - м. Київ (Україна)» за умови роботи 2 водіїв та використання автопоїзду у складі сідельного тягача MAN TGX 18.440 із напівпричепом-рефрижератором KÖGEL SV 24 наведені в табл. 2.

Таблиця 2 - Загальні витрати на виконання оборотного рейсу при виконанні турної їзди

\begin{tabular}{|l|c|}
\hline \multicolumn{1}{|c|}{ Стаття витрат } & Розмір витрат, грн. \\
\hline \multicolumn{1}{|c|}{1} & 2 \\
\hline Фонд заробітної плати водія & 9187,77 \\
\hline Витрати на автомобільне паливо & 44728,12 \\
\hline Витрати на мастильні матеріали & 5367,37 \\
\hline Витрати на сервісне обслуговування & 82,19 \\
\hline Витрати на відновлення і ремонт шин & 1500,72 \\
\hline Витрати на оформлення перевезення & 7606,00 \\
\hline Амортизаційні відрахування & 6253,0 \\
\hline Загальногосподарські витрати & 11208,78 \\
\hline & 85933,95 \\
\hline
\end{tabular}


На основі аналізу даних табл. 1, 2 можна виділити три основні фактори, що найбільше впливають на величину загальних витрат при виконанні оборотного рейсу у міжнародному сполученні (результуючу величину) - це фонд заробітної плати водія $X_{1}$, витрати на автомобільне паливо $X_{2}$ і загальногосподарські витрати $X_{3}$. Для проведення дослідження буде використаний план другого ступеня повного факторного експерименту ПФЕ ${ }^{3}$.

Завданням експерименту є отримання рівняння регресії, яке при дослідженні трьох факторів, має вигляд [5]:

$$
\begin{aligned}
& Y=b_{0}+b_{1} x_{1}+b_{2} x_{2}+b_{3} x_{3}+b_{11} x_{1}^{2}+b_{22} x_{2}^{2}+b_{33} x_{3}^{2}+b_{12} x_{1} x_{2}+,(1) \\
& +b_{13} x_{1} x_{3}+b_{23} x_{2} x_{3}+b_{123} x_{1} x_{2} x_{3}
\end{aligned}
$$

де

$b_{i j}$ - коефіцієнти регресіі;

$x_{1}, x_{2}, x_{3}-$ кодоване значення фактору.

Для формування плану другого ступеня повного факторного експерименту, в якому три фактори змінюються на двох рівнях (ПФЕ $\left.{ }^{3}\right)$, необхідно визначити інтервали змінювання кожного із досліджуваних факторів $-X_{i \min }, X_{i \max }$, нульовий рівень $X_{0 i}$ та напівдіапазон зміни фактору $\Delta X_{i}$. Для наведеного прикладу інтервали змінювання кожного із досліджуваних факторів $-X_{i \min }$ та $X_{i \max }$ визначені таким чином.

Для фактору $X_{1}$ (фонд заробітної плати водія, $\left.\Phi 3 П\right)$ :

- $X_{i \min }$ відповідає умові застосування одиночної їзди та чисельно дорівнює розрахованим витратам фонду заробітної плати водія ФЗП при виконанні оборотного рейсу;

- $X_{i \max }$ відповідає умові застосування турної їзди та чисельно дорівнює розрахованим витратам фонду заробітної плати водія ФЗП при виконанні оборотного рейсу.

Для фактору $X_{2}$ (витрати на автомобільне паливо, $C_{\Pi}$ ):

- $X_{i \min }$ відповідає умові використання автопоїзду у складі сідельного тягача MAN TGX 18.440 із напівпричепом-рефрижератором KÖGEL SV 24 вантажопідйомністю 27,056 т. Лінійна норма витрати палива становить 20,6 л/100 км. Значення витрат $C_{\Pi}$ чисельно дорівнює розрахованому значенню витрат на паливо при виконанні оборотного рейсу зазначеним автопоїздом;

- $X_{i \max }$ відповідає умові використання автопоїзду у складі сідельного тягача Renault MAGNUM 460.19 T із напівпричепом-рефрижератором KÖGEL SV 24 вантажопідйомністю 27,056 т для виконання оборотного рейсу. Лінійна норма витрати палива становить 22,8 л/100 км. Значення витрат $C_{\Pi}$ чисельно дорівнює розрахованому значенню витрат на паливо при виконанні оборотного рейсу зазначеним автопоїздом.

Для фактору $X_{3}$ (загальногосподарські витрати, $C_{3}$ ):

- $X_{i \min }$ відповідає умові застосування турної їзди і використання автопоїзду у складі сідельного тягача MAN TGX 18.440 із напівпричепом-рефрижератором KÖGEL SV 24, та чисельно дорівнює розрахованим витратам при виконанні оборотного рейсу двома водіями;

- $X_{i \max }$ відповідає умові застосування одиночної їзди і використання автопоїзду у складі сідельного тягача Renault MAGNUM 460.19 T із напівпричепом-рефрижератором KÖGEL SV 24, та чисельно дорівнює розрахованим витратам при виконанні оборотного рейсу одним водієм.

У табл. 3 наведені визначені та розраховані інтервали змінювання факторів.

Таблиця 3 - Інтервали змінювання факторів

\begin{tabular}{|l|c|c|c|c|}
\hline \multicolumn{1}{|c|}{ Фактори } & $\begin{array}{c}\text { Мінімум } \\
\left(X_{i \min }\right)\end{array}$ & $\begin{array}{c}\text { Максимум } \\
\left(X_{i \max }\right)\end{array}$ & $\begin{array}{c}\text { Нульовий } \\
\text { рівень }\left(X_{0 i}\right)\end{array}$ & $\begin{array}{c}\text { Напівдіапазон зміни } \\
\text { фактору }\left(\Delta X_{i}\right)\end{array}$ \\
\hline $\begin{array}{l}\text { Фонд заробітної плати водія, } \Phi 3 П, \\
\text { грн. }\end{array}$ & 7874,40 & 9187,77 & 8531,09 & 656,69 \\
\hline
\end{tabular}


() Сахно В.П., Шарай С.М., Мурований І.С., Поляков В.М. 2021

\begin{tabular}{|l|c|c|c|c|}
\hline \hline $\begin{array}{l}\text { Витрати на автомобільне паливо, } \\
C_{П}, \text { грн. }\end{array}$ & 44728,12 & 47195,99 & 45962,06 & 1233,94 \\
\hline $\begin{array}{l}\text { Загальногосподарські витрати, } C_{3}, \\
\text { грн. }\end{array}$ & 11208,78 & 11513,46 & 11361,12 & 152,34 \\
\hline
\end{tabular}

Враховуючи, що для дослідження обрано 3 фактори, необхідно скласти план другого ступеня повного факторного експерименту. Для складання робочого плану експерименту необхідно скласти матрицю ортогонального плану. Для цього визначаються натуральні та кодовані значення досліджуваних факторів. Перехід від кодованих змінних до натуральних і навпаки виконується за наступними залежностями:

$$
\begin{gathered}
x_{i}=\frac{X_{i}-X_{0 i}}{\Delta X_{i}} ; \\
X_{i}=x_{i} \times \Delta X_{i}+X_{0 i},
\end{gathered}
$$

де $X_{i}, x_{i}$ - натуральне та кодоване значення фактору відповідно.

Для першого фактору - фонд заробітної плати водія, ФЗП: $X_{1}$ - натуральне значення фактору; $x_{1}$ - кодоване значення фактору. Для другого фактору - витрати на автомобільне паливо, $C_{\Pi}: X_{2}$ - натуральне значення фактору; $x_{2}$ - кодоване значення фактору. Для третього фактору загальногосподарські витрати, $C_{3}: X_{3}$ - натуральне значення фактору; $x_{3}$ - кодоване значення фактору.

Для виконання операції кодування натуральному значенню $X_{i \max }$ відповідає кодоване значення $x_{i}$ «+1», а значенню $X_{i \min }-$ відповідає кодоване значення $x_{i}$ «-1». Кодованому значенню $x_{0}$ відповідає значення «+1». Натуральне значення кожного фактору для «зіркової точки» («+1,215» або «-1,215») визначається шляхом множення цього кодованого значення на відповідне натуральне значення фактору («+1,215» - на максимальне значення, «-1,215» - на мінімальне).

Матриця ортогонального плану другого ступеня повного факторного експерименту, в якому три фактори змінюються на двох рівнях $\left(П Ф E^{3}\right)$, наведена в табл. 4.

Таблиця 4 - Організація матриці ПФЕ 3

\begin{tabular}{|c|c|c|c|c|c|c|c|}
\hline \multirow{2}{*}{$\begin{array}{c}\text { № } \\
\text { п/п }\end{array}$} & \multicolumn{2}{|c|}{ Кодовані значення факторів } & \multicolumn{3}{c|}{ Натуральні значення факторів } \\
\hline & $x_{0}$ & $x_{1}$ & $x_{2}$ & $x_{3}$ & $\Phi 3 П$, грн. $\left(X_{1}\right)$ & $C_{\Pi}$, грн. $\left(X_{2}\right)$ & $C_{3}$, грн. $\left(X_{3}\right)$ \\
\hline 1 & 2 & 3 & 4 & 5 & 6 & 7 & 8 \\
\hline 1 & +1 & +1 & +1 & +1 & 9187,77 & 47195,99 & 11513,46 \\
\hline 2 & +1 & -1 & +1 & +1 & 7874,40 & 47195,99 & 11513,46 \\
\hline 3 & +1 & +1 & -1 & +1 & 9187,77 & 44728,12 & 11513,46 \\
\hline 4 & +1 & -1 & -1 & +1 & 7874,40 & 44728,12 & 11513,46 \\
\hline 5 & +1 & +1 & +1 & -1 & 9187,77 & 47195,99 & 11208,78 \\
\hline 6 & +1 & -1 & +1 & -1 & 7874,40 & 47195,99 & 11208,78 \\
\hline 7 & +1 & +1 & -1 & -1 & 9187,77 & 44728,12 & 11208,78 \\
\hline 8 & +1 & -1 & -1 & -1 & 7874,40 & 44728,12 & 11208,78 \\
\hline 9 & +1 & $+1,215$ & 0 & 0 & 11163,14 & 45962,06 & 11361,12 \\
\hline 10 & +1 & $-1,215$ & 0 & 0 & 9567,40 & 45962,06 & 11361,12 \\
\hline 11 & +1 & 0 & $+1,215$ & 0 & 8531,09 & 57343,13 & 11361,12 \\
\hline 12 & +1 & 0 & $-1,215$ & 0 & 8531,09 & 54344,67 & 11361,12 \\
\hline 13 & +1 & 0 & 0 & $+1,215$ & 8531,09 & 45962,06 & 13988,85 \\
\hline 14 & +1 & 0 & 0 & $-1,215$ & 8531,09 & 45962,06 & 13618,67 \\
\hline 15 & +1 & 0 & 0 & 0 & 8531,09 & 45962,06 & 11361,12 \\
\hline
\end{tabular}

Робочий план експерименту наведений в табл. 5. 
Таблиця 5 - Кодовані і натуральні значення факторів $\Phi 3 П, C_{\Pi}, C_{3}$ та функції відгуку $C(y)$

\begin{tabular}{|c|c|c|c|c|c|c|c|}
\hline \multirow{2}{*}{} & \multicolumn{2}{|c|}{$\Phi 3 \Pi$} & \multicolumn{2}{c|}{$C_{\Pi}$} & \multicolumn{2}{c|}{$C_{3}$} & $C(y)$ \\
\cline { 2 - 7 } & $x_{1}$ & $X_{1}$ & $x_{2}$ & $X_{2}$ & $x_{3}$ & $X_{3}$ & $y$ \\
\hline 1 & +1 & 9187,77 & +1 & 47195,99 & +1 & 11513,46 & 89144,85 \\
\hline 2 & -1 & 7874,40 & +1 & 47195,99 & +1 & 11513,46 & 87831,48 \\
\hline 3 & +1 & 9187,77 & -1 & 44728,12 & +1 & 11513,46 & 86676,98 \\
\hline 4 & -1 & 7874,40 & -1 & 44728,12 & +1 & 11513,46 & 85363,61 \\
\hline 5 & +1 & 9187,77 & +1 & 47195,99 & -1 & 11208,78 & 88840,17 \\
\hline 6 & -1 & 7874,40 & +1 & 47195,99 & -1 & 11208,78 & 87526,80 \\
\hline 7 & +1 & 9187,77 & -1 & 44728,12 & -1 & 11208,78 & 86372,30 \\
\hline 8 & -1 & 7874,40 & -1 & 44728,12 & -1 & 11208,78 & 85058,93 \\
\hline 9 & $+1,215$ & 11163,14 & 0 & 45962,06 & 0 & 11361,12 & 89733,95 \\
\hline 10 & $-1,215$ & 9567,40 & 0 & 45962,06 & 0 & 11361,12 & 88138,21 \\
\hline 11 & 0 & 8531,09 & $+1,215$ & 57343,13 & 0 & 11361,12 & 98482,97 \\
\hline 12 & 0 & 8531,09 & $-1,215$ & 54344,67 & 0 & 11361,12 & 95484,51 \\
\hline 13 & 0 & 8531,09 & 0 & 45962,06 & $+1,215$ & 13988,85 & 89729,63 \\
\hline 14 & 0 & 8531,09 & 0 & 45962,06 & $-1,215$ & 13618,67 & 89359,45 \\
\hline 15 & 0 & 8531,09 & 0 & 45962,06 & 0 & 11361,12 & 87101,90 \\
\hline
\end{tabular}

В цій матриці величина загальних витрат (функції відгуку) на виконання оборотного рейсу у міжнародному сполученні $C(y)$ розраховується з урахування значень досліджуваних факторів (табл. 1) та витрат, які входять до складу загальних витрат, але не мають суттєвого впливу на них, прийнятих як постійна величина, грн:

$$
C(y)=X_{1}+X_{2}+X_{3}+A_{\text {const }},
$$

де $C(y)$ - загальні витрати на виконання оборотного рейсу у міжнародному сполученні, грн;

$X_{1}, X_{2}, X_{3}$ - натуральні значення факторів, вплив яких досліджується, грн;

$A_{\text {const }}$ - сума витрат, які входять до складу загальних витрат, але не мають суттєвого впливу на них (витрати на мастильні матеріали, витрати на сервісне обслуговування, витрати на відновлення і ремонт шин, амортизаційні відрахування, витрати на оформлення перевезення), грн.

Завданням експерименту $\epsilon$ отримання рівняння регресії. Результати експерименту представляться поліномом другого ступеня, який при застосуванні трьох факторів має вигляд:

$$
y=b_{0}+\sum_{1 \leq i \leq k} b_{i} \times x_{i}+\sum_{1 \leq i \leq j \leq k} b_{i j} \times x_{i} \times x_{j}+\sum_{1 \leq i \leq k} b_{i i} \times x_{i}^{2}
$$

де

$y$ - величина функції відгуку;

$b_{i j}$ - коефіцієнти регресії;

$x_{i j}$ - кодовані значення факторів експерименту;

$k$ - кількість прийнятих факторів ( $k=3$ ).

Таким чином, якщо кількість факторів $k=3$, рівняння регресії для визначення витрат на виконання оборотного рейсу у міжнародному сполученні матиме вигляд:

$$
C=b_{0}+b_{1} x_{1}+b_{2} x_{2}+b_{3} x_{3}+b_{12} x_{1} x_{2}+b_{13} x_{1} x_{3}+b_{23} x_{2} x_{3}+b_{11} x_{1}^{2}+b_{22} x_{2}^{2}+b_{33} x_{3}^{2} .
$$


Для забезпечення ортогональності здійснюється перетворення моделі (5) до виду:

$$
y=b_{0}^{\prime}+\sum_{i=1}^{k} b_{i} \times x_{i}+\sum_{i \prec j}^{k} b_{i j} \times x_{i} \times x_{j}+\sum_{i=1}^{k} b_{i i} \times x_{i}^{\prime},(7)
$$

де

$b_{0}^{\prime}-$ вільний член рівняння;

$b_{i}, b_{i j}, b_{i i}$ - коефіцієнти (змінні) рівняння;

$x_{i}, x_{j}, x_{i}^{\prime}-$ кодовані значення факторів та їх похідних.

Вільний член рівняння та коефіцієнти (змінні) розраховуються за виразами:

$$
\begin{aligned}
& b_{0}^{\prime}=\frac{\sum_{u=1}^{N} m_{u} \times y_{c p_{u}}}{\sum_{u=1}^{N} m_{u}}=\frac{m \times \sum_{u=1}^{N} y_{c p_{u}}}{m \times N}=\frac{\sum_{u=1}^{N} y_{c p_{u}}}{N} ; \\
& b_{i}=\frac{\sum_{u=1}^{N} m_{u} \times x_{i_{u}} \times y_{c p_{u}}}{\sum_{u=1}^{N} m_{u} \times x_{i_{u}}^{2}}=\frac{m \times \sum_{u=1}^{N} x_{i_{u}} \times y_{c p_{u}}}{m \times \sum_{u=1}^{N} x_{i_{u}}^{2}}=\frac{\sum_{u=1}^{N} x_{i_{u}} \times y_{c p_{u}}}{\sum_{u=1}^{N} x_{i_{u}}^{2}} \\
& b_{i j}=\frac{\sum_{u=1}^{N} m_{u} \times\left(x_{i} \times x_{j}\right)_{u} \times y_{c p_{u}}}{\sum_{u=1}^{N} m_{u} \times\left(x_{i} \times x_{j}\right)_{u}^{2}}=\frac{m \times \sum_{u=1}^{N}\left(x_{i} \times x_{j}\right)_{u} \times y_{c p_{u}}}{m \times \sum_{u=1}^{N}\left(x_{i} \times x_{j}\right)_{u}^{2}}=\frac{\sum_{u=1}^{N}\left(x_{i} \times x_{j}\right)_{u} \times y_{c p_{u}}}{\sum_{u=1}^{N}\left(x_{i} \times x_{j}\right)_{u}^{2}} ; \\
& b_{i i}=\frac{\sum_{u=1}^{N} m_{u} \times x_{i_{u}}^{\prime} \times y_{c p_{u}}}{\sum_{u=1}^{N} m_{u} \times x_{i_{u}}^{\prime 2}}=\frac{m \times \sum_{u=1}^{N} x_{i_{u}}^{\prime} \times y_{c p_{u}}}{m \times \sum_{u=1}^{N} x_{i_{u}}^{2}}=\frac{\sum_{u=1}^{N} x_{i_{u}}^{\prime} \times y_{c p_{u}}}{\sum_{u=1}^{N} x_{i_{u}}^{\prime 2}} \\
& x_{i}^{\prime}=x_{i}^{2}-\lambda_{2},
\end{aligned}
$$

де $\quad \lambda_{2}-$ середній квадрат значень будь-якого фактора.

Середній квадрат значень будь-якого фактора визначається за формулою:

$$
\begin{gathered}
\lambda_{2}=N^{-1} \times \sum_{u=1}^{N} x_{i_{u}}^{2} \cdot(13) \\
\lambda_{2}=\frac{(+1)^{2}+(-1)^{2}+(+1)^{2}+(-1)^{2}+(+1)^{2}+(-1)^{2}+(+1)^{2}+(-1)^{2}+(+1,215)^{2}+(-1,215)^{2}}{15}=\frac{10,95}{15}=0,73 . \\
x_{i}^{\prime}=x_{i}^{2}-0,73 .
\end{gathered}
$$

Симетричний композиційний ортогональний план другого порядку для трьох факторів 3 одним дослідом в центрі плану наведено в табл. 6.

Таблиця 6 - Симетричний композиційний ортогональний план другого порядку

\begin{tabular}{|c|c|c|c|c|c|c|c|c|c|c|}
\hline & $x_{0}$ & $x_{1}$ & $x_{2}$ & $x_{3}$ & $x_{1} \times x_{2}$ & $x_{1} \times x_{3}$ & $x_{2} \times x_{3}$ & $x_{1}^{\prime}$ & $x_{2}^{\prime}$ & $x_{3}^{\prime}$ \\
\hline 1 & 1 & 1 & 1 & 1 & 1 & 1 & 1 & 0,27 & 0,27 & 0,27 \\
\hline 2 & 1 & -1 & 1 & 1 & -1 & -1 & 1 & 0,27 & 0,27 & 0,27 \\
\hline 3 & 1 & 1 & -1 & 1 & -1 & 1 & -1 & 0,27 & 0,27 & 0,27 \\
\hline
\end{tabular}


() Сахно В.П., Шарай С.М., Мурований І.С., Поляков В.М. 2021

\begin{tabular}{|c|c|c|c|c|c|c|c|c|c|c|}
\hline 4 & 1 & -1 & -1 & 1 & 1 & -1 & -1 & 0,27 & 0,27 & 0,27 \\
\hline 5 & 1 & 1 & 1 & -1 & 1 & -1 & -1 & 0,27 & 0,27 & 0,27 \\
\hline 6 & 1 & -1 & 1 & -1 & -1 & 1 & -1 & 0,27 & 0,27 & 0,27 \\
\hline 7 & 1 & 1 & -1 & -1 & -1 & -1 & 1 & 0,27 & 0,27 & 0,27 \\
\hline 8 & 1 & -1 & -1 & -1 & 1 & 1 & 1 & 0,27 & 0,27 & 0,27 \\
\hline 9 & 1 & 1,215 & 0 & 0 & 0 & 0 & 0 & 0,75 & $-0,73$ & $-0,73$ \\
\hline 10 & 1 & $-1,215$ & 0 & 0 & 0 & 0 & 0 & 0,75 & $-0,73$ & $-0,73$ \\
\hline 11 & 1 & 0 & 1,215 & 0 & 0 & 0 & 0 & $-0,73$ & 0,75 & $-0,73$ \\
\hline 12 & 1 & 0 & $-1,215$ & 0 & 0 & 0 & 0 & $-0,73$ & 0,75 & $-0,73$ \\
\hline 13 & 1 & 0 & 0 & 1,215 & 0 & 0 & 0 & $-0,73$ & $-0,73$ & 0,75 \\
\hline 14 & 1 & 0 & 0 & $-1,215$ & 0 & 0 & 0 & $-0,73$ & $-0,73$ & 0,75 \\
\hline 15 & 1 & 0 & 0 & 0 & 0 & 0 & 0 & $-0,73$ & $-0,73$ & $-0,73$ \\
\hline
\end{tabular}

Розраховані значення коефіцієнтів регресії перетвореної моделі наведені в табл. 7.

Таблиця 7 - Коефіцієнти регресії

\begin{tabular}{|c|c|c|c|c|c|c|c|c|c|}
\hline$b_{0}^{\prime}$ & $b_{1}$ & $b_{2}$ & $b_{3}$ & $b_{12}$ & $b_{13}$ & $b_{23}$ & $b_{11}$ & $b_{22}$ & $b_{33}$ \\
\hline 88989,72 & 656,83 & 1234,21 & 152,37 & 0,00 & 0,00 & 0,00 & $-3292,43$ & 2164,86 & $-2879,82$ \\
\hline
\end{tabular}

Значення коефіцієнтів регресії підставляються у рівняння регресії для визначення загальних витрат на виконання оборотного рейсу у міжнародному сполученні (6):

$C=b_{0}+b_{1} x_{1}+b_{2} x_{2}+b_{3} x_{3}+b_{12} x_{1} x_{2}+b_{13} x_{1} x_{3}+b_{23} x_{2} x_{3}+b_{11} x_{1}^{2}+b_{22} x_{2}^{2}+b_{33} x_{3}^{2}$.

Отримаємо:

$C=88989,72+656,83+1234,21+152,37+0+0+0+(-3292,43)+2164,86+(-2879,82)=87025,74$.

Розраховуємо похибку:

$$
\begin{gathered}
\Delta=\frac{\mathrm{C}(\mathrm{y})_{(+1,+1,+1)}-\mathrm{C}}{\mathrm{C}(\mathrm{y})_{(+1,+1,+1)}} \times 100 \% ; \\
\Delta=\frac{89144,85-87025,74}{89144,85} \times 100=2,377 \approx 2,4 \% .
\end{gathered}
$$

\section{ОБГОВОРЕННЯ РЕЗУЛЬТАТІВ ДОСЛІДЖЕННЯ}

3 використанням математичного апарату теорії планування експерименту при формуванні плану експерименту, створенні експериментально-статистичної моделі та визначенні вагомості впливу факторів на результуючу величину - загальні витрати на виконання оборотного рейсу доставки вантажів - визначаються фактори, які мають найбільшу вагу. Фактори вибираються із розрахованих для різних умов виконання оборотного рейсу статей витрат, які входять до складу загальних витрат. Умови виконання перевезень можуть розрізнятися способом організації роботи водіїв (турна чи одиночна їзда), використанням різного за витратами палива автотранспортного засобу, умовами страхування вантажу та автотранспортного засобу тощо.

За допомогою теорії планування експерименту можна практично реалізувати дослідний експеримент і визначити впливові та мало впливові на результуючу величину фактори, а кількість дослідів факторного експерименту може приблизно визначати кількість факторів, вплив яких на кінцевий результат буде підлягати дослідженню.

\section{ВИСНОВКИ}

На основі проведених досліджень можна зробити такі висновки: 
за допомогою теорії планування експерименту розроблена експериментальностатистична модель для розрахунку загальних витрат на виконання оборотного рейсу доставки вантажів у міжнародному сполученні;

розраховані значення окремих коефіцієнтів регресії $b_{1}, b_{2}, b_{3}$, а також їх квадратів $b_{11}$, $b_{22}, b_{33}$ показують, що найбільшу значущість мають коефіцієнти $b_{2}$ i $b_{22}$, тобто витрати на автомобільне паливо;

розраховані значення парних коефіцієнтів регресії $b_{12}, b_{13}, b_{23}$ показують, що комбінації досліджуваних факторів суттєво не впливають на значення загальних витрат на виконання оборотного рейсу;

похибка розрахунку загальних витрат на виконання оборотного рейсу у міжнародному сполученні за експериментально-статистичною моделлю з використанням теорії експерименту не перевищує 2,4%, що є допустимим при використанні таких моделей.

\section{ПЕРЕЛІК ДЖЕРЕЛ ПОСИЛАННЯ}

1. Грищук Ю.С. Основи наукових досліджень: Навч. посібник. / Ю.С. Грищук. - Харків: НТУ «ХПІ», 2008. - $232 \mathrm{c}$.

2. Аністратенко В.О., Федоров В.Г. Математичне планування експериментів в АПК. / В.О. Аністратенко, В.Г. Федоров. - Київ: Вища школа, 2005. - 375 с.

3. Кислий В.М. Організація наукових досліджень: Навч. посібник. / В.М. Кислий. - Суми: Університетська книга, 2011. - 224 с.

4. Полтавець В.В. Планування і обробка даних наукового експерименту: Конспект лекцій. / В.В. Полтавець. - Донецьк: ДВНЗ ДонНТУ, 2008 - 52 с.

5. Статюха Г.О., Складанний Д.М., Бондаренко О.С. Вступ до планування оптимального експерименту: Навч. посібник. / Г.О. Статюха, Д.М. Складанний, О.С. Бондаренко. - К.: ІВЦ «Політехніка», 2011. - $117 \mathrm{c}$.

6. Давідіч Ю.О. Конспект лекцій з дисципліни «Моделювання транспортних систем» (для магістрів усіх форм навчання спеціальності 275 - Транспортні технології) / Ю.О. Давідіч, Г.І. Фалецька; Харків. нац. ун-т. міськ. госп-ва ім. О. М. Бекетова. - Харків: ХНУМГ ім. О. М. Бекетова, 2019. $-71 \mathrm{c}$.

\section{REFERENCES}

1. Hryshchuk Yu.S. Osnovy naukovykh doslidzhen: Navch. posibnyk. / Yu.S. Hryshchuk. Kharkiv: NTU «KhPI», 2008. - 232 s.

2. Anistratenko V.O., Fedorov V.G. Matematychne planuvannia eksperymentiv v APK. / V.O. Anistratenko, V.G. Fedorov. - Kyiv: Vyshcha shkola, 2005. - 375 s.

3. Kyslyi V.M. Orhanizatsiia naukovykh doslidzhen: Navch. posibnyk. / V.M. Kyslyi. - Sumy: Universytetska knyha, 2011. - 224 s.

4. Poltavets V.V. Planuvannia i obrobka danykh naukovogo eksperymentu: Konspekt lektsii. / V.V. Poltavets. - Donetsk: DVNZ DonNTU, 2008 - 52 s.

5. Statiukha H.O., Skladannyi D.M., Bondarenko O.S. Vstup do planuvannia optymalnoho eksperymentu: Navch. posibnyk. / G.O. Statiukha, D.M. Skladannyi, O.S. Bondarenko. - K.: IVTs «Politekhnika», 2011. - 117 s.

6. Davidich Yu.O. Konspekt lektsii z dystsypliny «Modeliuvannia transportnykh system» (dlia mahistriv usikh form navchannia spetsialnosti 275 - Transportni tekhnolohii) / Yu.O. Davidich, H.I. Faletska; Kharkiv. nats. un-t. misk. hosp-va im. O. M. Beketova. - Kharkiv: KhNUMH im. O. M. Beketova, 2019. - $71 \mathrm{~s}$.

V. Sakhno, S. Sharai, I. Murovanyi, V. Polyakov. Investigations of factors influence on the total costs of the implementation of turnaround flight in international transportation with using mathematical theory of experiment.

The paper considers the issues of the impact of different items of total costs (factors) on the amount of such total costs in the implementation of a return flight of the delivery of goods by road in international traffic.

To develop the measures to improve the efficiency of the process of transportation of goods in international traffic and reduce the total cost of its implementation, it is necessary to analyze the cost items 
that are the part of the total costs. To study the impact of separate items of total costs on the implementation of cargo transportation in international traffic, it is proposed to use effective methods of practical realization of a systematic approach - the methods of mathematical theory of experiment or experiment planning. Thus the decision of a problem of research of influence of separate articles of expenses (factors of influence) on the size of the total costs is carried out on the basis of formation of the plan of experiment and creation of experimental-statistical model/

As a result of calculations of regression coefficients according to the developed model of total costs for the implementation of a return flight in international traffic and their analysis, conclusions were made about the significance of the coefficients that have the greatest impact on total costs and identified the items of costs (investigated factors of influence), which have the greatest influence on the formation of total costs.

Keywords: total costs, cost item, international cargo transportation, return flight, influencing factor, theory of planning of experiment.

САХНО Володимир Прохорович, доктор технічних наук, професор, завідувач кафедри автомобілів Національного транспортного університету, e-mail: sakhno@ntu.edu.ua. https://orcid.org/0000-0002-5144-7131

ШАРАЙ Світлана Михайлівна, кандидат технічних наук, доцент, професор кафедри міжнародних перевезень та митного контролю Національного транспортного університету, e-mail: Svetasharai@gmail.com. http://orcid.org/0000-0001-6568-4990

МУРОВАНИЙ Ігор Сергійович, кандидат технічних наук, доцент, декан факультету транспорту та механічної інженерії Луцького національного технічного університету, e-mail: igor_lntu@ukr.net. https://orcid.org/0000-0002-9749-980X

ПОЛЯКОВ Віктор Михайлович, кандидат технічних наук, доцент, професор кафедри автомобілів Національного транспортного університету, e-mail: poljakov_2006@ukr.net. https://orcid.org/0000-0001-7042-3066

Volodymyr SAKHNO, Doctor of Science in Engineering, Professor, Head of Automobiles Department, National Transport University, e-mail: sakhno@ntu.edu.ua. https://orcid.org/0000-0002-5144$\underline{7131}$

Svitlana SHARAI, PhD. in Engineering, Associate Professor, Professor, Department of International Transport and Customs Control, National Transport University, e-mail: Svetasharai@gmail.com http://orcid.org/0000-0001-6568-4990

Igor MUROVANYI, PhD. in Engineering, Assoc. Professor, Dean of the Faculty of Transport and Mechanical Engineering, Lutsk National Technical University, e-mail: igor_lntu@ukr.net. https://orcid.org/0000-0002-9749-980X

Victor POLYAKOV, Ph.D., associate professor, professor of «Automobiles», National Transport University, e-mail: poljakov_2006@ukr.net. https://orcid.org/0000-0001-7042-3066.

DOI 10.36910/automash.v1i16.518 